\title{
Theoretical research of the force field of (difluoroamino)trinitromethane in the coordinates $\mathrm{X}_{\delta}{ }^{0}$
}

\author{
C) Olga S. Averyanova, and Alexander V. Belik*+ \\ Faculty of Chemical Technology and Computing Chemistry. Chelyabinsk State University. Kashyrinych Br. \\ St, 129. Chelyabinsk, 454001.Russia.Phone:+7 (351)799-70-66.E-mail: belik@csu.ru
}

*Supervising author; ${ }^{+}$Corresponding author

Keywords: $\mathrm{F}_{2} \mathrm{NC}\left(\mathrm{NO}_{2}\right)_{3}$, (difluoroamino)trinitromethane, the generalized force constants, coordinates $\mathrm{X}_{\delta}{ }^{0}$, calculations DFT, vibration frequencies.

\begin{abstract}
Actual problem of modern chemists-researchers is studying the properties of molecules of compounds. The latest achievements in the field of computer engineering and quantum chemistry make it possible to research various physicochemical parameters of studying compounds using theoretical calculations. Calculation methods can greatly simplify the task, as they are safer and more economical than experiment. It is noted that methane derivatives are also currently of interest for research in connection with their widespread use. This paper is devoted to the study of the force fields of molecule of (difluoroamino)trinitromethane using quantum chemical calculations.

The Becke-Lee-Yang-Parr method of density functional theory (DFT) B3LYP with a hybrid potential of 6-311++G(3df, 3pd) was chosen as the main approximation for the work performed, since when using it, the best quality of the result is noted. Also, in the present work, as an alternative to chemical (natural) coordinates, new coordinates $\mathrm{X}_{\delta}^{0}$ were chosen, which allows one to take into account torsional vibrations. The calculations presented in this work were performed using the Gaussian and GaussView programs, designed to calculate a large number of properties and characteristics of chemical reactions.

In this paper, using the proposed approach, the geometry of the molecule of (difluoroamino)trinotromethane has been optimized, the geometric parameters of these compound were considered, in particular, the valence angles, dihedral angles, and long bonds were calculated, corresponding to the minimum energy of this molecule. For the first time, generalized force coefficients for $\mathrm{F}_{2} \mathrm{NC}\left(\mathrm{NO}_{2}\right)_{3}$ were calculated, and the "stiffness" of the chemical compounds of the molecule under study was evaluated. The frequencies of normal vibrations (wave numbers) for the studied compound in the harmonic approximation were calculated and analyzed. A comparison of the obtained wave numbers with experimental data is given. The results obtained indicate a satisfactory agreement between theory and experiment. A general view of the vibrational spectrum of (difluoroamino)trinotromethane obtained as a result of quantum chemical calculations is presented. The conclusion is drawn about the possibilities of applying the B3LYP 6-311++G(3df, 3pd) approach for calculating the frequencies of normal vibrations and force coefficients.
\end{abstract}

\section{References}

[1] H. Feuer. The chemistry of the nitro and nitroso groups. Part 1: translation from English Moscow: Mir. 1975. 536p. (russian)

[2] S.S. Novikov, G.A. Shvehgeymer, V.V. Sevostyanova, V.A. Shlyapochnicov. The chemistry of aliphatic and acyclic compounds. Moscow: Chemistry. 1974. 416p. (russian)

[3] W. Kohn. Electronic structure of matter - wave functions and density functionals. UFN (Nobel Lecture 1998). 2002. Vol.172. No.3. P.336-348.

[4] A.D. Becke. Density-functional thermochemistry. III. The role of exact exchange. J. Chem. Phys. 1993. Vol.98. P.5648-5652.

[5] F. Jensen. Introduction to Computational Chemistry. Sec. Ed., Chichester: John Wiley \& Sons Ltd. The Atrium, Southern Gate. 2007. 599p.

[6] A.V. Belik. New aspects of computational chemistry: a monograph. Chelyabinsk: Polygraph-Master. 2015. 200p. (russian)

[7] D.V. Savchik, V.P. Balykin, A.V. Belik. Solving the vibrational problem using $\mathrm{X}_{\delta}{ }^{0}$ coordinates using an example of an ammonia molecule. Chelyabinsk: Messenger of Chelyabinsk State University. Physics. 2010. No.12 (193). Iss.7. P.73-77. (russian) 
THEORETICAL RESEARCH OF THE FORCE FIELD OF (DIFLUOROAMINO)TRINITROMETHANE IN... 102-106

[8] I.V. Tokmakov, V.A. Shlyapochnikov. Using the theory of hybrid electron density functional (hybrid DFT) to calculate vibrational spectra: nitromethane. Bulletin of the Russian Academy of Sciences. Chemistry. 1997. No.12. P.2106-2109. (russian)

[9] L.S. Mayants, G.B. Shaltuper. A new approach to the full calculation of the vibrations of any molecules. USSR Academy of Sciences report. 1972. No.206. P.657-660. (russian)

[10] L.S. Mayants, G.B. Shaltuper. General methods of analysing molecular vibrations. J. Mol. Struct. 1975. Vol.24. P.409-431.

[11] M.J. Frisch, G.W. Trucks, H.B. Schlegel et al. Gaussian 09, Revision A.02. Gaussian, Inc., Wallingford CT. 2009.

[12] E.V. Butyrskaya. Computer Chemistry: Fundamentals of Theory and Work with Gaussian and GaussView Programs. Moscow: SOLON-PRESS. 2011. 224p. (russian)

[13] E.I. Fedotova, and A.V. Belik. Nitrocompounds: structure, force coefficients in coordinates $\mathrm{X}_{\delta}{ }^{0}$ and the frequencies of normal vibrations of $\mathrm{NO}_{2}$-group. Butlerov Communications. 2012. Vol.31. No.9. C.2935. ROI-jbc-02/12-31-9-29

[14] E.I. Fedotova, A.V. Belik. Effect of the number of nitro groups in a molecule on the force fields of nitroalkanes. Chelyabinsk: Messenger of Chelyabinsk State University. Physics. 2011. No.39. Iss.12. P.42-47. (russian)

[15] V.A. Shlyapochnikov, D.V. Levchenkov, A.B. Kharitonkin. Vibrational spectra of trinitromethane derivatives. Rus. Chem. Bull. 2001. Vol.50. No.7. P.1173-1180. 